\title{
Profile of lacosamide and its role in the long-term treatment of epilepsy: a perspective from the updated NICE guideline
}

This article was published in the following Dove Press journal:

Neuropsychiatric Disease and Treatment

5 April 2013

Number of times this article has been viewed

\author{
Vanessa Delgado Nunes' \\ Laura Sawyer ${ }^{2}$ \\ Julie Neilson' \\ Grammati Sarri' \\ J Helen Cross ${ }^{3,4}$
}

'National Clinical Guideline Centre, Royal College of Physicians, London, UK; ${ }^{2}$ Symmetron Limited, Elstree, UK; ${ }^{3} \mathrm{UCL}$ Institute of Child Health, Great Ormond Street Hospital for Children, London, UK; ${ }^{4}$ Young Epilepsy, Lingfield, UK
Correspondence: Vanessa Delgado Nunes National Clinical Guideline Centre,

Royal College of Physicians,

II St Andrews Place, NWI 4LE, London, UK

Tel +4402030751277

Fax +44020 763। 5097

Email vanessa.nunes@rcplondon.ac.uk
Aim: The goal of antiepileptic treatment is to achieve seizure freedom or seizure control. The aim of this paper is to review the evidence for the use of lacosamide for adjunctive treatment of refractory focal seizures with or without secondary generalization, within the scope of the 2012 update of the Clinical Guideline published by the National Institute for Health and Clinical Excellence (NICE).

Methods: Clinical evidence for the use of lacosamide and other antiepileptic drugs (AEDs) was systematically reviewed, evaluated, and presented to the Guideline Development Group. Only randomized clinical trials were included. Outcomes of clinical efficacy (seizure freedom, $50 \%$ reduction in seizure frequency, time to first seizure, time to 12 -month remission, treatment withdrawal, and time to treatment withdrawal), experience of adverse events, and cognitive and quality of life outcomes were reviewed. A decision model was built to weigh the clinical benefits of each adjunctive AED, measured by seizure control and seizure reduction, compared with the harm from adverse events, as measured by withdrawals from treatment due to adverse events.

Results: Lacosamide was included as part of the recommended AEDS to be used in tertiary epilepsy centers. The evidence review showed that more participants who received lacosamide as an adjunctive treatment had at least a 50\% reduction in seizure frequency compared with those taking placebo. However, more participants on lacosamide were found to experience adverse events and withdrawal from treatment compared with those on placebo. The cost-effectiveness analysis showed that compared with placebo, the benefits gained from adjunctive lacosamide were modest and uncertain, whereas the costs were significantly high. Compared with other AEDs licensed for adjunctive therapy in focal seizures, lacosamide was associated with fewer quality-adjusted life years and higher costs. Therefore, the Guideline Development Group noted that the balance of benefit and harm needs to be carefully monitored in all patients.

Keywords: focal seizures, anti-epileptic drug, adjunctive therapy, clinical guideline

\section{Introduction}

Epilepsy is defined as a neurological condition characterized by recurrent epileptic seizures unprovoked by any immediately identifiable cause. An epileptic seizure is the clinical manifestation of an abnormal and excessive discharge of a set of neurons in the brain. ${ }^{1}$ Epileptic seizures should be viewed as a symptom with many different causes and not as a single disease entity. Epilepsy is therefore more accurately termed the epilepsies.

Diagnosis can be challenging, making accurate prevalence estimates difficult. With a prevalence of active epilepsy of 5-10 cases per $1000,{ }^{2}$ epilepsy has been estimated to affect between 362,000 and 415,000 people in England, with a further 
5\%-30\% (up to another 124,500 people) misdiagnosed with epilepsy. ${ }^{3}$ Consequently, a physician or pediatrician with expertise in epilepsy should diagnose and manage the condition.

Focal seizures, by definition, arise from networks limited to one hemisphere. ${ }^{4}$ They are the most common seizure type in adults and children. The mainstay of treatment for epilepsy are the antiepileptic drugs (AEDs), taken daily to prevent the recurrence of epileptic seizures. Seizure freedom remains the goal of therapy, although in some individuals, optimal seizure control may be more achievable. Treatment success has been most recently defined by the International League Against Epilepsy as a seizure-free duration that is at least three times the longest seizure-free interval prior to starting the new treatment, with a sustained response over 12 months. $^{5}$

The 2004 guideline from the National Institute of Health and Clinical Excellence (NICE) on the management of the epilepsies in adults and children was partially updated in January 2012, with regard to drug management. Update of the 2004 guideline was driven mainly by the fact that a further five AEDs had become licensed for use in the UK for the treatment of epilepsy in the intervening years, as well as by the publication of the Standard and New Antiepileptic Drug (SANAD) trial. ${ }^{6}$

Lacosamide is licensed in the UK for adjunctive treatment of refractory focal seizures with or without secondary generalization. Although, like other AEDs (eg, carbamazepine, lamotrigine), it acts on voltage-gated sodium channels, it is believed to do so by enhancing slow inactivation rather than stabilizing fast inactivation. ${ }^{7}$ It was included in the systematic review of clinical evidence and original cost-effectiveness analysis of different pharmacological interventions for epilepsy in adults with refractory focal seizures in the 2012 update. Here, we review the evidence for lacosamide alongside other AEDs for the treatment of refractory focal seizures, collected as part of the guideline update.

\section{Methods}

\section{Clinical evidence methods}

The Guideline Development Group (GDG) comprised a psychiatrist (chair), two patient members, two pediatric neurologists (one of whom was the clinical adviser), two adult neurologists, a general practitioner, a pediatrician, a clinical pharmacologist, and two specialist nurses.

The GDG followed the standard NICE methods in the development of this guideline. ${ }^{8}$ This involved systematically searching, critically appraising, and summarizing of the clinical and cost-effectiveness evidence for the clinical areas identified as most relevant for the scope of the guideline. The group also conducted a new cost-effectiveness analysis, comparing different antiepileptic drugs as adjunctive treatments in focal seizures.

\section{GRADE (Grading of Recommendations \\ Assessment, Development, and Evaluation)}

The evidence for the outcomes of studies was evaluated and presented using an adaptation of the GRADE toolbox ${ }^{9}$ developed by the international GRADE working group. The software (GRADEpro; Cochrane IMS, Copenhagen, Denmark) was used to assess pooled outcome data, using individual study quality assessments and results from metaanalyses. Further information on the software and main criteria considered in the rating can be found in the GRADE working group publications. ${ }^{9-14}$

\section{Types of studies}

We included only randomized controlled trials (RCTs) as these are considered the most robust type of study design for producing an unbiased estimate of intervention effects. However, there are some limitations that need to be highlighted. First, regulatory trials in epilepsy usually have only a limited period of follow up, and therefore, true efficacy may not be apparent. They can also sometimes use dosing regimens that are not entirely in line with clinical practice. Therefore, the study dosages were always checked for accordance with the therapeutic ranges listed in the British National Formulary and the maximum and minimum doses specified in the Summary of Product Characteristics. Any trial dose outside these ranges was not included in the meta-analysis. For RCTs, the main criteria considered for the evidence review were:

- An appropriate and clearly focused question was addressed.

- Appropriate randomization, allocation, and concealment methods were used.

- Subjects, investigators, and outcomes assessors were masked about treatment allocation.

- The intervention and control groups were similar at baseline.

- The only difference between groups was the type of intervention received.

- All outcomes were measured using a standard and reliable method. 
- Drop-out rates were reported and were acceptable, and all participants were analyzed in the groups to which they were randomly allocated the treatment.

- For multicenter trials, results were comparable between sites.

For the comparisons for which blinded trials were not available, the GDG downgraded the level of outcome quality, due to the higher risk of bias. However, the difficulty of blinding in these trials, and the trade-off between possible higher bias in unblinded studies and the wider clinical applicability, were taken into consideration in the decision making by the GDG.

We included noninferiority, equivalence, and superiority studies but did not include single-arm noncomparative trials. Dose-response trials without a comparative drug or placebo arm were therefore excluded. We did not include responseselected trials whereby only participants who responded to a drug were included in the trial. The results of these studies would have been biased towards the drug as the participant had already responded to it.

No particular time duration for the potential studies was specified for our inclusion criteria.

\section{Types of participants}

Adults and children were included in the evidence reviews. For other reviews undertaken as part of the guideline, evidence pertaining to adults was kept separate from that relating to children. However, for adjunctive therapy, we were guided by recent European Medicines Agency (EMA) decisions ${ }^{15}$ regarding licensing of AEDS for use in children. These indicate that

focal epilepsies in children older than 4 years old have a similar clinical expression to focal epilepsies in adolescents and adults. [...] [T]he results of efficacy trials performed in adults could to some extent be extrapolated to children provided the dose is established. ${ }^{15}$

As a result of this, and with the agreement of the GDG, data for adults and children were combined for the purposes of the evidence review of AEDs in the treatment of refractory focal seizures.

The evidence reviews were structured according to epilepsy seizure type or syndrome, as it was agreed that this would be most clinically meaningful. This would also allow for the potential for a given AED to be established as therapeutic for a specific seizure type (or syndrome or population). In clinical practice, the choice of AED at presentation should be dictated by the specific epilepsy syndrome where possible, but where unclear, the seizure type (or most likely epilepsy syndrome, by age of onset) provides a guide to treatment in the first instance.

\section{Types of outcome measures and definitions}

The following outcomes were considered to be the most important for clinical decision making in the guideline:

- The proportion of seizure-free participants: participants seizure-free over a defined period during maintenance.

- The proportion of participants experiencing at least a $50 \%$ reduction in seizure frequency (ie, responders): those experiencing a $>50 \%$ reduction in seizures over a defined end-of-maintenance period compared with baseline.

- The proportion of participants having treatment withdrawn: the proportion of participants who were withdrawn from the study prior to the predefined time period of maintenance treatment.

- Time to exit/withdrawal from allocated treatment (retention time): period of time from randomization to exit from treatment (withdrawal from treatment), either for lack of efficacy seizures or adverse events.

- Time to first seizure: time from randomization to first seizure.

- Time to 12-month remission: time from randomization to the achievement of a 12-month period without seizures.

- Incidence of adverse events ( $10 \%$ or above): incidence of reported adverse event at any time during study period, as reported within the study, as a proportion of total randomized patients ( $>10 \%$ taken as significant for reporting).

- Any outcomes relating to cognitive effects.

- Any outcomes relating to quality of life.

Only validated measures of cognitive effect and quality of life were analyzed in this evidence review.

The GDG considered the outcome of more than a 50\% reduction of seizures from baseline as the most important outcome for adjunctive therapy in refractory focal seizures. This was based on the purpose of the monotherapy, which is for the individual to achieve seizure freedom with minimal, if any side effects. However, when initial drugs have failed and adjunctive treatment is used, seizure reduction is likely to be the aim.

The GDG recognized that many of the studies were performed over a relatively short period of time and that the majority used these measures as the primary outcome 
variables. The GDG also agreed not to restrict the time period for measurement of the outcomes. The most ideal measure of effect would appear to be time to exit from study, whether due to lack of efficacy or adverse events, as a measure of retention on the medication. However, limited studies appear to have reported these data. Where available, this outcome was utilized. The GDG recognized that the most reliable measure of efficacy (seizure freedom) and retention was likely to be the time to 12-month remission.

Most included trials reported the incidence of a range of adverse events. The GDG agreed on using an arbitrary cutoff point of above an incidence of $10 \%$, to prioritize the list of adverse events retrieved from the trials, as they considered $10 \%$ to be a well-established proportion for an adverse event.

\section{Type of analysis}

Estimates of effect from individual trials were based on intention-to-treat data, that is, all participants included in the randomization process are considered in the final analysis, based on the treatment groups to which they were originally assigned. In order to allow for the inclusion of all of the studies, regardless of the type of data they presented, and to be considered in an equivalent manner, all data considered in this review were based on true intention-to-treat populations. Thus in several cases, we needed to recalculate the data reported in the studies, based on the assumption that missing participants did not experience the event of interest.

Meta-analyses were conducted to combine the results of studies for each clinical question, using Cochrane Review Manager (RevMan 5; Cochrane IMS) software. Fixed or random effects techniques were used to calculate risk ratios (relative risk [RR]) for the binary outcomes, and the continuous outcomes were analyzed using an inverse variance method for pooling weighted mean differences. Statistical heterogeneity was assessed by considering the chi-squared test for significance at $P<0.05$ or an I-squared inconsistency statistic of $>50 \%$, to indicate significant heterogeneity.

\section{Health economics methods}

One of the unique characteristics of the NICE guidelines is their consideration of cost effectiveness. It is important to investigate whether health technologies and services represent reasonable value for money. If, for example, a particular treatment strategy was found to yield little health gain relative to the resources used, then it would be more advantageous to redeploy resources to other activities that yield a greater health gain.

In accordance with the NICE social-value-judgments paper, ${ }^{16}$ an intervention is determined to be cost effective if it dominates other relevant strategies (that is, it is both less costly in terms of resource use and more clinically effective compared with all the other relevant alternative strategies), or if it costs less than $£ 20,000$ per quality-adjusted life year (QALY) gained compared with the next best strategy.

Cost-effectiveness is determined by comparing strategies to one another; hence, key outcomes of health economic analysis are incremental. These outcomes include

- Incremental cost: the mean cost of one strategy minus the mean cost of a comparator strategy.

- QALYs gained: the mean QALYs associated with one strategy minus the mean QALYs of a comparator strategy.

- Incremental cost-effectiveness ratio: the incremental cost divided by the respective QALYs gained.

- Incremental net benefit (INB): the (monetary) value of a strategy compared with an alternative strategy, for a given cost-effectiveness threshold (for example: $£ 20,000$ per QALY gained).

The INB of each strategy is estimated using the following formula:

\section{$\mathrm{INB}=(\mathrm{QALYs}$ gained compared with a baseline drug $\times £ 20,000)$ - the incremental cost compared with a baseline drug.}

This indicates that, in the UK, the National Health Service (NHS) will invest up to $£ 20,000$ to gain one additional QALY. The strategy that has the highest INB is the optimal (that is, most cost-effective) strategy. Strategies that have a negative INB are not cost effective compared with the baseline drug.

\section{Validation}

The draft guideline went through a rigorous reviewing process, in which stakeholder organizations were invited to comment; the group took all comments into consideration when producing the final version of the guideline.

\section{Results}

\section{Clinical evidence}

We searched for any RCT comparing the effectiveness of two or more different pharmacological interventions for 
epilepsy in adults with refractory focal epilepsy, against a placebo. We included in our search strategy all the interventions currently used for the treatment of refractory focal epilepsy (acetazolamide, carbamazepine, clobazam, clonazepam, eslicarbazepine acetate, felbamate, gabapentin, lacosamide, lamotrigine, levetiracetam, oxcarbazepine, phenytoin, pregabalin, phenobarbital, primidone, sodium valproate, sulthiame, tiagabine, topiramate, vigabatrin, and zonisamide).

Three RCTs ${ }^{17-19}$ were identified that compared lacosamide (200 and $400 \mathrm{mg}$ ) as adjunctive therapy versus placebo, for adults with partial-onset seizures with or without secondary generalizations. No RCT was found to compare lacosamide with other AEDs for children, young people, or adults with refractory focal seizures.

All three multicenter RCTs included only adults with partial onset seizures for at least 2 years, without any seizurefree period longer than 21 days during the $4-8$ weeks prior to their enrolment to the trial. Pregnant women or adults with a history of alcohol or drug abuse were excluded.

All three trials lasted 24-26 weeks (8-week baseline period, 4-6 week titration, and 12-week maintenance period).

Two of the three included studies ${ }^{18,19}$ had low risk of bias, as assessed by GRADE criteria, whereas the third $\mathrm{RCT}^{1}$ had a high risk of bias, as there was no information regarding its blinding, method of randomization, and allocation concealment. In addition, two of the studies ${ }^{1,4}$ had high drop-out rates in the lacosamide groups compared with placebo. Table 1 shows full details of the quality assessment of included studies (following GRADE criteria).

Results from the meta-analysis of the three RCTs, with 1105 participants, suggested that lacosamide, as an adjunctive treatment, is more clinically effective than placebo in increasing the proportion of patients with at least a $50 \%$ reduction in seizure frequency (RR 1.67 [1.35 to 2.07]), though the confidence in this effect is low due to the very serious limitations of the overall quality assessment (Table 1).

No difference was found between the efficacy of lacosamide and placebo with regards to achievement of seizure freedom and for the proportion of patients who withdrew due to lack of efficacy.

In terms of experience of adverse events, it was found that lacosamide given as adjunctive treatment may cause a significantly higher proportion of adults with refractory epilepsy to withdraw due to adverse events compared with placebo (RR 2.91 [1.79 to 4.72]). There was a significantly higher proportion of patients on lacosamide adjunctive therapy, compared with those on placebo, who experienced dizziness, vomiting, diplopia, or blurred vision, although there was uncertainty in terms of the magnitude of the clinical effect of the last three adverse events (Table 1). No difference was found between lacosamide and placebo, for headache, fatigue, upper respiratory infection, somnolence, and nausea, although the confidence in these results is very low, as there were very serious study limitations.

No evidence was found for the other efficacy outcomes, such as time to first seizure, time to exit/withdrawal of allocated treatment, time to 12-month remission, and cognitive or quality of life outcomes.

\section{Health economics evidence}

At the time the systematic review of health economic literature was undertaken, no studies evaluating the cost effectiveness of lacosamide as adjunctive therapy in the treatment of refractory focal epilepsy were identified. An original economic model was developed to compare all licensed AEDs, including lacosamide, used as adjunctive therapy in adults with refractory focal seizures. The analysis took a UK National Health Service perspective, with costs expressed in 2009-2010 pound sterling. A 15-year time horizon was considered relevant and sufficiently long enough to capture the important costs and consequences of treatment. The expected costs and benefits, expressed as QALYs, were estimated for the time spent on each therapy. The performance of alternative AEDs was estimated using incremental cost effectiveness ratios (defined as the added cost of a given strategy divided by its added benefit, compared with the next most expensive strategy). The effectiveness of different AEDs was based on clinical evidence from pair-wise meta-analyses of placebo-controlled trials.

Results for lacosamide are summarized in Table 2 and indicate that as adjunctive therapy, it is associated with increased costs (£2849) and improved health outcomes (0.043 more QALYs) compared with continuation of existing therapy alone (placebo). Although the expected additional costs of lacosamide are statistically significant ( $95 \%$ confidence interval [CI]: $£ 570$ to $£ 5128$ more), the expected benefits are more uncertain (95\% CI: 1.277 fewer QALYs to 1.363 more QALYs). The incremental cost-effectiveness ratio for lacosamide compared with placebo is $£ 66,256$ per QALY gained, placing it beyond the NICE-willingness-topay threshold of $£ 20,000$.

Compared with the mean costs and benefits of other adjunctive therapies currently licensed for the treatment of 
Table I Clinical evidence profile: lacosamide versus placebo

\begin{tabular}{|c|c|c|c|c|c|}
\hline No of studies & Design & Risk of bias & Inconsistency & Indirectness & Imprecision \\
\hline \multicolumn{6}{|c|}{ At least $\mathbf{5 0 \%}$ reduction in seizure frequency } \\
\hline $\begin{array}{l}\text { 3: Ben-Menachem et al; } ;^{17} \\
\text { Halász et al; }{ }^{18} \text { Chung et al }{ }^{19}\end{array}$ & $\begin{array}{l}\text { Randomized trials: } \\
\text { two double blinded, } \\
\text { one unblinded }\end{array}$ & Very serious ${ }^{\mathrm{a}, \mathrm{b}}$ & $\begin{array}{l}\text { No serious } \\
\text { inconsistency }\end{array}$ & $\begin{array}{l}\text { No serious } \\
\text { indirectness }\end{array}$ & $\begin{array}{l}\text { No serious } \\
\text { imprecision }\end{array}$ \\
\hline \multicolumn{6}{|l|}{ Seizure freedom } \\
\hline $\begin{array}{l}\text { 3: Ben-Menachem et al; }{ }^{17} \\
\text { Halász et al; }{ }^{18} \text { Chung et al }{ }^{19}\end{array}$ & $\begin{array}{l}\text { Randomized trials: } \\
\text { two double blinded, } \\
\text { one unblinded }\end{array}$ & Very serious ${ }^{\mathrm{a}, \mathrm{b}}$ & $\begin{array}{l}\text { No serious } \\
\text { inconsistency }\end{array}$ & $\begin{array}{l}\text { No serious } \\
\text { indirectness }\end{array}$ & $\begin{array}{l}\text { Very serious } \\
\text { imprecisionc }\end{array}$ \\
\hline \multicolumn{6}{|c|}{ Withdrawal due to adverse events } \\
\hline $\begin{array}{l}\text { 3: Ben-Menachem et al; } ;^{17} \\
\text { Halász et al; }{ }^{18} \text { Chung et al }{ }^{19}\end{array}$ & $\begin{array}{l}\text { Randomized trials: } \\
\text { two double blinded, } \\
\text { one unblinded }\end{array}$ & Very serious ${ }^{\mathrm{a}, \mathrm{b}}$ & $\begin{array}{l}\text { No serious } \\
\text { inconsistency }\end{array}$ & $\begin{array}{l}\text { No serious } \\
\text { indirectness }\end{array}$ & $\begin{array}{l}\text { No serious } \\
\text { imprecision }\end{array}$ \\
\hline \multicolumn{6}{|c|}{ Withdrawal due to lack of efficacy } \\
\hline $\begin{array}{l}\text { 3: Ben-Menachem et al; } ;^{17} \\
\text { Halász et al; }{ }^{18} \text { Chung et al }{ }^{19}\end{array}$ & $\begin{array}{l}\text { Randomized trials: } \\
\text { two double blinded, } \\
\text { one unblinded }\end{array}$ & Very serious $\mathrm{s}^{\mathrm{a}, \mathrm{b}}$ & $\begin{array}{l}\text { No serious } \\
\text { inconsistency }\end{array}$ & $\begin{array}{l}\text { No serious } \\
\text { indirectness }\end{array}$ & $\begin{array}{l}\text { Very serious } \\
\text { imprecision }^{c}\end{array}$ \\
\hline \multicolumn{6}{|l|}{ Incidence of diplopia } \\
\hline I: Chung et al ${ }^{19}$ & $\begin{array}{l}\text { Randomized trial: } \\
\text { double blinded }\end{array}$ & Serious ${ }^{b}$ & $\begin{array}{l}\text { No serious } \\
\text { inconsistency }\end{array}$ & $\begin{array}{l}\text { No serious } \\
\text { indirectness }\end{array}$ & $\begin{array}{l}\text { Serious } \\
\text { imprecision }^{d}\end{array}$ \\
\hline \multicolumn{6}{|l|}{ Incidence of dizziness } \\
\hline $\begin{array}{l}\text { 3: Ben-Menachem et al; } ;^{17} \\
\text { Halász et al; }{ }^{18} \text { Chung et al }{ }^{19}\end{array}$ & $\begin{array}{l}\text { Randomized trials: } \\
\text { two double blinded, } \\
\text { one unblinded }\end{array}$ & Very serious ${ }^{\mathrm{a}, \mathrm{b}}$ & $\begin{array}{l}\text { No serious } \\
\text { inconsistency }\end{array}$ & $\begin{array}{l}\text { No serious } \\
\text { indirectness }\end{array}$ & $\begin{array}{l}\text { No serious } \\
\text { imprecision }\end{array}$ \\
\hline \multicolumn{6}{|l|}{ Incidence of headache } \\
\hline $\begin{array}{l}\text { 2: Ben-Menachem et al; } ;^{17} \\
\text { Chung et al }{ }^{19}\end{array}$ & $\begin{array}{l}\text { Randomized trials: } \\
\text { one double blinded, } \\
\text { one unblinded }\end{array}$ & Very serious ${ }^{\mathrm{a}, \mathrm{b}}$ & $\begin{array}{l}\text { No serious } \\
\text { inconsistency }\end{array}$ & $\begin{array}{l}\text { No serious } \\
\text { indirectness }\end{array}$ & $\begin{array}{l}\text { Very serious } \\
\text { imprecision }{ }^{c}\end{array}$ \\
\hline \multicolumn{6}{|l|}{ Incidence of nausea } \\
\hline $\begin{array}{l}\text { 2: Ben-Menachem et al; } ;^{17} \\
\text { Chung et al }{ }^{19}\end{array}$ & $\begin{array}{l}\text { Randomized trials: } \\
\text { one double blinded, } \\
\text { one unblinded }\end{array}$ & Very serious ${ }^{\mathrm{a}, \mathrm{b}}$ & $\begin{array}{l}\text { No serious } \\
\text { inconsistency }\end{array}$ & $\begin{array}{l}\text { No serious } \\
\text { indirectness }\end{array}$ & $\begin{array}{l}\text { Very serious } \\
\text { imprecision }^{c}\end{array}$ \\
\hline \multicolumn{6}{|l|}{ Incidence of fatigue } \\
\hline I: Ben-Menachem et al ${ }^{17}$ & $\begin{array}{l}\text { Randomized trial: } \\
\text { unblinded }\end{array}$ & Very serious ${ }^{\mathrm{a}, \mathrm{b}}$ & $\begin{array}{l}\text { No serious } \\
\text { inconsistency }\end{array}$ & $\begin{array}{l}\text { No serious } \\
\text { indirectness }\end{array}$ & $\begin{array}{l}\text { Very serious } \\
\text { imprecision }^{c}\end{array}$ \\
\hline \multicolumn{6}{|l|}{ Incidence of vomiting } \\
\hline I: Ben-Menachem et al ${ }^{17}$ & $\begin{array}{l}\text { Randomized trial: } \\
\text { unblinded }\end{array}$ & Very serious ${ }^{\mathrm{a}, \mathrm{b}}$ & $\begin{array}{l}\text { No serious } \\
\text { inconsistency }\end{array}$ & $\begin{array}{l}\text { No serious } \\
\text { indirectness }\end{array}$ & $\begin{array}{l}\text { Serious } \\
\text { imprecision }^{d}\end{array}$ \\
\hline \multicolumn{6}{|l|}{ Incidence of URI } \\
\hline $\mathrm{I}:$ Ben-Menachem et $\mathrm{al}^{17}$ & $\begin{array}{l}\text { Randomized trial: } \\
\text { unblinded }\end{array}$ & Very serious ${ }^{\mathrm{a}, \mathrm{b}}$ & $\begin{array}{l}\text { No serious } \\
\text { inconsistency }\end{array}$ & $\begin{array}{l}\text { No serious } \\
\text { indirectness }\end{array}$ & $\begin{array}{l}\text { Very serious } \\
\text { imprecision }^{c}\end{array}$ \\
\hline \multicolumn{6}{|l|}{ Incidence of blurred vision } \\
\hline I: Chung et al ${ }^{19}$ & $\begin{array}{l}\text { Randomized trial: } \\
\text { double blinded }\end{array}$ & $\begin{array}{l}\text { Serious } \\
\text { limitations }^{\mathrm{b}}\end{array}$ & $\begin{array}{l}\text { No serious } \\
\text { inconsistency }\end{array}$ & $\begin{array}{l}\text { No serious } \\
\text { indirectness }\end{array}$ & $\begin{array}{l}\text { Serious } \\
\text { imprecision }^{d}\end{array}$ \\
\hline \multicolumn{6}{|l|}{ Incidence of somnolence } \\
\hline I: Chung et al ${ }^{19}$ & $\begin{array}{l}\text { Randomized trial: } \\
\text { double blinded }\end{array}$ & $\begin{array}{l}\text { Serious } \\
\text { limitations }^{\mathrm{b}}\end{array}$ & $\begin{array}{l}\text { No serious } \\
\text { inconsistency }\end{array}$ & $\begin{array}{l}\text { No serious } \\
\text { indirectness }\end{array}$ & $\begin{array}{l}\text { Very serious } \\
\text { imprecision }^{c}\end{array}$ \\
\hline
\end{tabular}

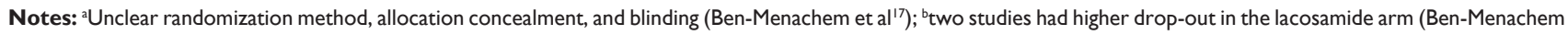
et $\mathrm{al}^{17}$ and Chung et $\mathrm{al}^{19}$ ); ${ }^{\mathrm{C}}$ wide confidence intervals around the estimate of the effect relative to the clinically important threshold; ${ }^{\circ}$ limited number of events.

Abbreviations: $\mathrm{Cl}$, confidence interval; $\mathrm{RR}$, relative risk; URI, upper respiratory infection.

refractory focal seizures (Table 3), including gabapentin, lamotrigine, levetiracetam, oxcarbazepine, pregabalin, tiagabine, and topiramate, the model found lacosamide likely to be more costly and to generate slightly fewer QALYs; however, these differences did not reach significance.
These results were consistent across a range of sensitivity analyses. The cost-effectiveness rank was calculated based on the incremental net benefit for each drug compared with placebo, at a willingness-to-pay threshold of $£ 20,000$ per QALY gained. 


\begin{tabular}{|c|c|c|c|c|c|c|}
\hline \multirow{2}{*}{$\begin{array}{l}\text { Other } \\
\text { considerations }\end{array}$} & \multicolumn{2}{|c|}{ No of patients } & \multicolumn{2}{|l|}{ Effect } & \multirow[t]{2}{*}{ Quality } & \multirow[t]{2}{*}{ Importance } \\
\hline & Lacosamide & Placebo & Relative $(95 \% \mathrm{CI})$ & Absolute & & \\
\hline None & $\begin{array}{l}276 / 741 \\
(37.2 \%)\end{array}$ & $\begin{array}{l}81 / 364 \\
(22.3 \%)\end{array}$ & $\begin{array}{l}\text { RR I.67 } \\
\text { (I.35 to } 2.07)\end{array}$ & $\begin{array}{l}149 \text { more per } 1000 \\
\text { (from } 78 \text { more to } 238 \text { more) }\end{array}$ & $\begin{array}{l}\bullet \bullet \circ \circ \\
\text { Low }\end{array}$ & Critical \\
\hline None & $\begin{array}{l}|8 / 74| \\
(2.4 \%)\end{array}$ & $\begin{array}{l}3 / 364 \\
(0.8 \%)\end{array}$ & $\begin{array}{l}\text { RR } 2.34 \\
(0.8 \text { to } 6.86)\end{array}$ & $\begin{array}{l}\text { II more per } 1000 \\
\text { (from } 2 \text { fewer to } 48 \text { more) }\end{array}$ & $\begin{array}{l}\bullet \circ \circ \circ \\
\text { Very low }\end{array}$ & Critical \\
\hline None & $\begin{array}{l}107 / 74 \mid \\
(14.4 \%)\end{array}$ & $\begin{array}{l}18 / 364 \\
(4.9 \%)\end{array}$ & $\begin{array}{l}\text { RR } 2.91 \\
\text { (I.79 to } 4.72)\end{array}$ & $\begin{array}{l}94 \text { more per } 1000 \\
\text { (from } 39 \text { more to } 184 \text { more) }\end{array}$ & $\begin{array}{l}\bullet \bullet \circ \circ \\
\text { Low }\end{array}$ & Critical \\
\hline None & $\begin{array}{l}6 / 741 \\
(0.8 \%)\end{array}$ & $\begin{array}{l}5 / 364 \\
(1.4 \%)\end{array}$ & $\begin{array}{l}\text { RR } 0.59 \\
(0.18 \text { to } 1.93)\end{array}$ & $\begin{array}{l}6 \text { fewer per } 1000 \\
\text { (from II fewer to } 13 \text { more) }\end{array}$ & $\begin{array}{l}\bullet \circ \circ 0 \\
\text { Very low }\end{array}$ & Critical \\
\hline None & $\begin{array}{l}21 / 204 \\
(10.3 \%)\end{array}$ & $\begin{array}{l}3 / 104 \\
(2.9 \%)\end{array}$ & $\begin{array}{l}\text { RR } 3.57 \\
\text { (I.09 to II.69) }\end{array}$ & $\begin{array}{l}74 \text { more per } 1000 \\
\text { (from } 3 \text { more to } 308 \text { more) }\end{array}$ & $\begin{array}{l}\bullet \bullet \circ \circ \\
\text { Low }\end{array}$ & Important \\
\hline None & $\begin{array}{l}|82 / 74| \\
(24.6 \%)\end{array}$ & $\begin{array}{l}29 / 364 \\
(8 \%)\end{array}$ & $\begin{array}{l}\text { RR } 3.08 \\
(2.13 \text { to } 4.44)\end{array}$ & $\begin{array}{l}166 \text { more per } 1000 \\
\text { (from } 90 \text { more to } 274 \text { more) }\end{array}$ & $\begin{array}{l}\bullet \bullet \circ \circ \\
\text { Low }\end{array}$ & Important \\
\hline None & $\begin{array}{l}64 / 419 \\
(15.3 \%)\end{array}$ & $\begin{array}{l}21 / 201 \\
(10.4 \%)\end{array}$ & $\begin{array}{l}\text { RR I.46 } \\
(0.91 \text { to } 2.32)\end{array}$ & $\begin{array}{l}48 \text { more per } 1000 \\
\text { (from } 9 \text { fewer to } 138 \text { more) }\end{array}$ & $\begin{array}{l}\bullet \circ \circ 0 \\
\text { Very low }\end{array}$ & Important \\
\hline None & $\begin{array}{l}51 / 419 \\
(12.2 \%)\end{array}$ & $\begin{array}{l}|4 / 20| \\
(7 \%)\end{array}$ & $\begin{array}{l}\text { RR I.73 } \\
\text { (0.99 to } 3.05)\end{array}$ & $\begin{array}{l}51 \text { more per } 1000 \\
\text { (from I fewer to } 143 \text { more) }\end{array}$ & $\begin{array}{l}\bullet \circ \circ 0 \\
\text { Very low }\end{array}$ & Important \\
\hline None & $\begin{array}{l}24 / 215 \\
(11.2 \%)\end{array}$ & $\begin{array}{l}5 / 97 \\
(5.2 \%)\end{array}$ & $\begin{array}{l}\text { RR } 2.17 \\
(0.85 \text { to } 5.5 \mathrm{I})\end{array}$ & $\begin{array}{l}61 \text { more per } 1000 \\
\text { (from } 8 \text { fewer to } 235 \text { more) }\end{array}$ & $\begin{array}{l}\bullet \circ \circ 0 \\
\text { Very low }\end{array}$ & Important \\
\hline None & $\begin{array}{l}24 / 215 \\
(11.2 \%)\end{array}$ & $\begin{array}{l}3 / 97 \\
(3.1 \%)\end{array}$ & $\begin{array}{l}\text { RR } 3.61 \\
\text { (I.II to II.7) }\end{array}$ & $\begin{array}{l}81 \text { more per } 1000 \\
\text { (from } 3 \text { more to } 332 \text { more) }\end{array}$ & $\begin{array}{l}\bullet \circ \circ 0 \\
\text { Very low }\end{array}$ & Important \\
\hline None & $\begin{array}{l}25 / 215 \\
(11.6 \%)\end{array}$ & $\begin{array}{l}1 \mathrm{I} / 97 \\
(1 \mathrm{I} .3 \%)\end{array}$ & $\begin{array}{l}\text { RR I.03 } \\
(0.53 \text { to } 2)\end{array}$ & $\begin{array}{l}3 \text { more per } 1000 \\
\text { (from } 53 \text { fewer to } 113 \text { more) }\end{array}$ & $\begin{array}{l}\bullet \circ \circ 0 \\
\text { Very low }\end{array}$ & Important \\
\hline None & $\begin{array}{l}23 / 204 \\
(11.3 \%)\end{array}$ & $\begin{array}{l}3 / 104 \\
(2.9 \%)\end{array}$ & $\begin{array}{l}\text { RR } 3.91 \\
(1.2 \text { to } 12.72)\end{array}$ & $\begin{array}{l}84 \text { more per } 1000 \\
\text { (from } 6 \text { more to } 338 \text { more) }\end{array}$ & $\begin{array}{l}\bullet \bullet \circ \circ \\
\text { Low }\end{array}$ & Important \\
\hline None & $\begin{array}{l}21 / 204 \\
(10.3 \%)\end{array}$ & $\begin{array}{l}7 / 104 \\
(6.7 \%)\end{array}$ & $\begin{array}{l}\text { RR I.53 } \\
\text { (0.67 to } 3.48)\end{array}$ & $\begin{array}{l}36 \text { more per } 1000 \\
\text { (from } 22 \text { fewer to } 167 \text { more) }\end{array}$ & $\begin{array}{l}\bullet \circ 00 \\
\text { Very low }\end{array}$ & Important \\
\hline
\end{tabular}

\section{Linking evidence to recommendations}

As part of the guideline development and stemming from the evidence review, the GDG deliberated that if first-line treatments are ineffective or not tolerated, carbamazepine, lamotrigine, levetiracetam, oxcarbazepine, sodium valproate, topiramate, clobazam, or gabapentin, should be offered as adjunctive treatment to children, young people, and adults, with focal seizures. Furthermore, it was recommended that 
Table 2 Results of the cost-effectiveness analysis of adjunctive lacosamide

\begin{tabular}{llll}
\hline & Placebo & Lacosamide & Increments \\
\hline Mean costs $(95 \% \mathrm{Cl})$ & $£ 8928(8315$ to 9595$)$ & $£ \mid I, 777(\mid 0,017$ to I4,39I) & $£ 2849(570$ to $5 \mid 28)$ \\
Mean QALYs $(95 \% \mathrm{Cl})$ & $8.197(7.086$ to 8.984$)$ & $8.24(7.175$ to $9.01 \mathrm{I})$ & $0.043(-1.277$ to I.363) \\
ICER $(€ /$ QALY) & & & $£ 66,256$ \\
\hline
\end{tabular}

Abbreviations: $\mathrm{Cl}$, confidence interval; ICER, incremental cost-effectiveness ratio; QALY, quality-adjusted life year.

when adjunctive treatment is not effective or not tolerated in children, young people, or adults, with refractory focal seizures, the following recommendation should apply:

[O]ther AEDs that may be considered by the tertiary epilepsy specialist are eslicarbazepine acetate, lacosamide, phenobarbital, phenytoin, pregabalin, tiagabine, vigabatrin and zonisamide. Carefully consider the risk-benefit ratio when using vigabatrin because of the risk of an irreversible effect on visual fields. ${ }^{20}$

The recommendation was based on evidence of both clinical and cost effectiveness, and the proportion of people achieving a $50 \%$ reduction in seizure frequency was considered to be critical for decision-making. Lacosamide was included as part of the recommended AEDS to be used in a tertiary epilepsy center. This was based on the direct evidence for adults with focal-onset seizures for at least 2 years that showed that more participants who received lacosamide as an adjunctive treatment had at least 50\% reduction in seizure frequency compared with those taking placebo. From the evidence reviewed, other AEDs, such as zonisamide, eslicarbazepine acetate, tiagabine, vigabatrin, and pregabalin, were also found to show evidence of efficacy in some patients and may benefit those who have not responded to and/or who have experienced adverse effects with AEDs. The guideline assumed that prescribers will use a drug's summary of product characteristics to inform decisions made with individual patients, and recommended some drugs for indications for which they did not have a UK marketing authorisation at the date of publication, if there was good evidence to support that use.

However, from the evidence retrieved, more participants on lacosamide experienced adverse events and withdrawal from treatment compared with those on placebo. Therefore, the GDG noted that the balance of benefit and harm needs to be carefully monitored in all patients. Further, it must be recognized that different individuals may have different responses to various AEDs. A significant consideration in this recommendation, based on clinical expertise, was the recognition that vigabatrin has a harmful and irreversible side-effects profile, as it is associated with retinal toxicity causing visual impairment. These side effects occur over the longer term and were not observed in any of the short-term trials combined in the analysis.

The evidence reviewed in relation to the clinical effectiveness of lacosamide as an adjunctive treatment had serious limitations. The quality of the evidence was low, as most of the trials that were included in the evidence base had unclear or no details of the randomization, allocation concealment, or blinding that was done and had a higher dropout rate in the lacosamide arm. Therefore, the estimates of lacosamide effect need to be interpreted with caution.

Table 3 Total costs and benefits of all adjunctive AEDs compared to placebo

\begin{tabular}{|c|c|c|c|c|}
\hline Adjunctive AED & Total cost $(€)$ & $\begin{array}{l}\text { Total benefit } \\
\text { (QALYs) }\end{array}$ & $\begin{array}{l}\text { ICER vs placebo } \\
\text { (£/QALY) }\end{array}$ & $\begin{array}{l}\text { INB vs placebo at } \\
20 \mathrm{k} \text { threshold }(\boldsymbol{t}) \\
\text { (cost-effectiveness rank) }\end{array}$ \\
\hline Placebo & 8928 & 8.197 & & $0(6)$ \\
\hline Gabapentin & 9394 & 8.255 & 8034 & $694(3)$ \\
\hline Lamotrigine & 9431 & 8.264 & 7507 & $837(1)$ \\
\hline Oxcarbazepine & 10,564 & 8.314 & 13,983 & $704(2)$ \\
\hline Topiramate & 10,606 & 8.302 & $|5,98|$ & $422(4)$ \\
\hline Levetiracetam & 11,157 & 8.316 & $|8,73|$ & $151(5)$ \\
\hline Pregabalin & $|1,29|$ & 8.301 & 22,721 & $-283(7)$ \\
\hline Tiagabine & 11,673 & 8.281 & 32,679 & $-1065(8)$ \\
\hline Lacosamide & $\mathrm{II}, 777$ & 8.24 & 66,256 & $-1989(9)$ \\
\hline Zonisamide & 13,237 & 8.26 & 68,397 & $-3049(\mathrm{II})$ \\
\hline Eslicarbazepine acetate & 13,322 & 8.279 & 53,585 & $-2754(10)$ \\
\hline
\end{tabular}

Abbreviations: AED, antiepileptic drug; ICER, incremental cost-effectiveness ratio; INB, incremental net benefit; QALY, quality-adjusted life year. 
A decision model was built to weigh the clinical benefits of each adjunctive AED, measured by seizure control and seizure reduction, compared with the harm from adverse events, as measured by withdrawals from treatment due to adverse events. Compared with placebo, the benefits gained from adjunctive lacosamide were modest and uncertain, whereas the costs were significantly high. Compared with other AEDs licensed for adjunctive therapy in focal seizures, lacosamide was associated with fewer QALYs and higher costs. Therefore, the GDG felt that lacosamide, along with eslicarbazepine acetate, pregabalin, tiagabine, and zonisamide, should not be recommended among initial adjunctive therapy options. Rather, these drugs should be considered only for cases where other, more cost-effective drugs, such as gabapentin, lamotrigine, levetiracetam, oxcarbazepine, and topiramate, are contraindicated or have been tried and were either ineffective or not tolerated. The limitations of the original analyses, particularly where assumptions had to be made, related to a paucity of data on longer term effectiveness and discontinuation, limited health-state utility data, and the limited data to inform estimates of NHS resource use.

The GDG consensus opinion was that management should be discussed with patients or that they should be offered referral to a tertiary epilepsy specialist, if adjunctive treatment with AEDs is ineffective or not tolerated, because achieving successful treatment may be complex. They noted that long-term experience with some of these drugs (pregabalin, lacosamide, zonisamide, and eslicarbazepine acetate) is limited, and that future research, as outlined below, is needed.

\section{For future research}

The GDG identified the need for the following areas of future research, in terms of the evaluation of lacosamide and the other AEDs included in this evidence review, as first line monotherapy.

Within the purposes of the guideline development, it was discussed and agreed that research should include:

- A prospective, randomized, controlled trial (RCT).

- All ages.

- Subgroup analyses of seizure types and syndromes.

- Primary outcome of seizure-freedom.

- Secondary outcomes, including seizure reduction, quality of life, and cognitive outcome.

- An attempt to obtain some data on pharmacoresistance.

\section{Disclosure}

The authors report no conflicts of interest in this work.

\section{References}

1. Sander JW, Shorvon SD. Epidemiology of the epilepsies. J Neurol Neurosurg Psychiatry. 1996;61(5):433-443.

2. Services for Patients with Epilepsy: Report of a CSAG Committee Chaired by Professor Alison Kitson. London: Clinical Standards Advisory Group; 1999. Available from: http://webarchive.nationalarchives.gov.uk/+/www. dh.gov.uk/en/Publicationsandstatistics/Publications/PublicationsPolicyAndGuidance/DH_4009240. Accessed February 6, 2013.

3. Chowdhury FA, Nashef L, Elwes RD. Misdiagnosis in epilepsy: a review and recognition of diagnostic uncertainty. Eur J Neurol. 2008; 15(10):1034-1042.

4. Berg AT, Berkovic SF, Brodie MJ, et al. Revised terminology and concepts for organization of seizures and epilepsies: report of the ILAE Commission on Classification and Terminology, 2005-2009. Epilepsia. 2010;51(4):676-685.

5. Kwan P, Sperling MR. Refractory seizures: try additional antiepileptic drugs (after two have failed) or go directly to early surgery evaluation? Epilepsia. 2009;50 Suppl 8:57-62.

6. Marson AG, Appleton R, Baker GA, et al. A randomised controlled trial examining the longer-term outcomes of standard versus new antiepileptic drugs. The SANAD trial. Health Technol Assess. 2007; 11(37):1-134.

7. Krauss GL, Edwards HB, Lin B. Lacosamide for the treatment of epilepsy. Ann Med. 2012;44(7):674-679.

8. The Guidelines Manual. London: National Institute for Health and Clinical Excellence; 2009. Available from: http://www.nice.org.uk/media/615/64/ The_guidelines_manual_2009.pdf. Accessed February 6, 2013.

9. Guyatt GH, Oxman AD, Vist GE, et al; GRADE Working Group. GRADE: an emerging consensus on rating quality of evidence and strength of recommendations. BMJ. 2008;336(7650):924-926.

10. Guyatt GH, Oxman AD, Kunz R, et al; GRADE Working Group. Going from evidence to recommendations. BMJ. 2008;336(7652): 1049-1051.

11. Guyatt GH, Oxman AD, Kunz R, et al; GRADE Working Group. Incorporating considerations of resources use into grading recommendations. BMJ. 2008;336(7654):1170-1173.

12. Guyatt GH, Oxman AD, Kunz R, et al; GRADE Working Group. What is "quality of evidence" and why is it important to clinicians? BMJ. 2008;336(7651):995-998.

13. Jaeschke R, Guyatt GH, Dellinger P, et al; GRADE Working Group. Use of GRADE grid to reach decisions on clinical practice guidelines when consensus is elusive. BMJ. 2008;337:a744.

14. Schünemann HJ, Oxman AD, Brozek J, et al; GRADE Working Group. Grading quality of evidence and strength of recommendations for diagnostic tests and strategies. BMJ. 2008;336(7653):1106-1110.

15. Guideline on Clinical Investigation of Medicinal Products in the Treatment of Epileptic Disorders. London: European Medicines Agency; 2010. Available from: http://www.ema.europa.eu/docs/en_GB/ document_library/Scientific_guideline/2010/01/WC500070043.pdf. Accessed February 6, 2013.

16. Social Value Judgements: Principles for the Development of NICE Guidance, 2nd ed. London: National Institute for Health and Clinical Excellence; 2008. Available from: http://www.nice.org.uk/media/ C18/30/SVJ2PUBLICATION2008.pdf. Accessed February 6, 2013.

17. Ben-Menachem E, Biton V, Jatuzis D, Abou-Khalil B, Doty P, Rudd GD. Efficacy and safety of oral lacosamide as adjunctive therapy in adults with partial-onset seizures. Epilepsia. 2007;48(7):1308-1317.

18. Halász P, Kälviäinen R, Mazurkiewicz-Beldzińska M, et al; SP755 Study Group. Adjunctive lacosamide for partial-onset seizures: Efficacy and safety results from a randomized controlled trial. Epilepsia. 2009; 50(3):443-453.

19. Chung S, Sperling MR, Biton V, et al; SP754 Study Group. Lacosamide as adjunctive therapy for partial-onset seizures: a randomized controlled trial. Epilepsia. 2010;51(6):958-967.

20. The epilepsies: the diagnosis and management of the epilepsies in adults and children in primary and secondary care (clinical guidelines, CG137.) National Institute for Health and Clinical Excellence; 2012 [updated December 11, 2012]. Available from: http://guidance.nice.org. uk/CG137. Accessed February 6, 2013. 


\section{Publish your work in this journal}

Neuropsychiatric Disease and Treatment is an international, peerreviewed journal of clinical therapeutics and pharmacology focusing on concise rapid reporting of clinical or pre-clinical studies on a range of neuropsychiatric and neurological disorders. This journal is indexed on PubMed Central, the 'PsycINFO' database and CAS.

The manuscript management system is completely online and includes a very quick and fair peer-review system, which is all easy to use. Visit http://www.dovepress.com/testimonials.php to read real quotes from published authors.

\footnotetext{
Submit your manuscript here: http://www.dovepress.com/neuropsychiatric-disease-and-treatment-journal
} 